\title{
A Study on the Media Arts Using Interactive
}

\section{Projection Mapping}

\author{
Hyeyoung Yoo \\ Dept. of advanced image Graduate School of Advanced Imaging Science \\ Multimedia and Film, Chung-Ang University, Korea \\ Hyunggi Kim \\ Dept. of advanced image Graduate School of Advanced Imaging Science \\ Multimedia and Film, Chung-Ang University, Korea \\ Copyright (C) 2014 Hyeyoung Yoo and Hyunggi Kim. This is an open access article distributed \\ under the Creative Commons Attribution License, which permits unrestricted use, distribution, and \\ reproduction in any medium, provided the original work is properly cited.
}

\begin{abstract}
Digital technology has revolutionized the way we make and experience art today. As technology has been advanced, people are well acquainted with a variety of techniques for video display of visual imagery. People expect the light to be able to paint images that are as much as they can be to the dream world. Lately new media artist create an illusion of being mapping on surface of objects, structures, buildings and displayed in public spaces. A new trend of video mapping technology allow for interactive projection mapping. This study is focused on research on media arts using projection mapping techniques and based on these we produce a media art work "DYMANIC ROOM" through the conceptual development and the technical aspects of interactive video projection mapping.
\end{abstract}

Keywords: Illusion, Interactive, Media Arts, Projection Mapping, Joy Stick

\section{Introduction}

Video Mapping is one of the newest video projection techniques that are used to turn almost any surface into a dynamic video display. The aim of video mapping is to create a physical illusion of images by combining audio-visual 
elements. This technique is used by artists and advertisers alike who can add extra dimensions, optical illusions, and notions of movement onto previously static objects. Large companies such as Nokia, Samsung and BMW have since used video projections to create campaigns for their products in major cities across the world. This way, artists can show their work in any location as anything and anywhere can be a canvas. Interactive projection mapping works are usually to be controlled by the audience through sensors, buttons, or personal devices like smartphone or tablets. Since people participate in the live performance directly, they become immersed and feel interest in the art piece more.

\section{Related work}

The Urban Flipper is a giant interactive pinball created by 3D projection mapping, projected onto the facade of the Célestins theater in Lyon. It uses the relief of the facade such as windows, balconies and columns as part of playable pinball, all complemented by the sounds of the pinball. The public has been able to try out the pinball. With the traditional pings, pongs, bells and whistles, Urban Flippers give audience one of the coolest explorations for experience of the interactive projection mapping. This giant game of flipper, or pinball, could be played during the Festival of Light 2011 in Lyon, France. It designed by Carol Martin and Thibaut Berbezier who form the collective CT Light.

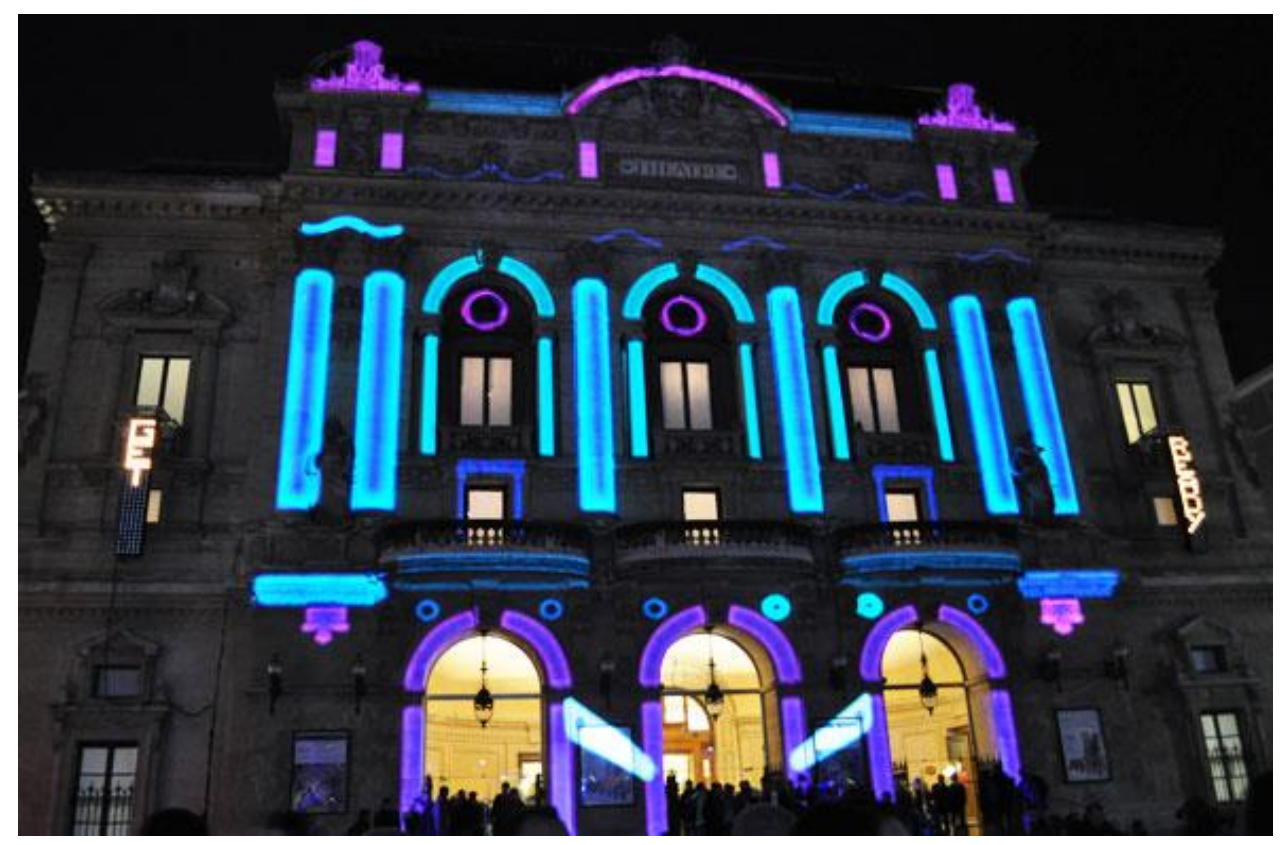

Fig. 1. Urban Flipper image

Like digital creatures set loose from the world of the movie Tron, two wild 
animals light up the night with dazzling displays of color illuminating their surfaces. Created by Sober Industries and Studio Rewind, the large scale sculptures featured the unlikely pairing of an owl and a rhinoceros. The two were displayed and covered with mapped visuals that could be spectator controlled. The spectators were able to control the visuals projected by a custom made cubicle with motion sensors and buttons. By tilting the cubicle the color of the visuals changed and the buttons were used to skip through the visuals and to create other effects like blending and scratching. The sculptures are made entirely out of wood and can be disassembled to smaller pieces which are easier to transport.

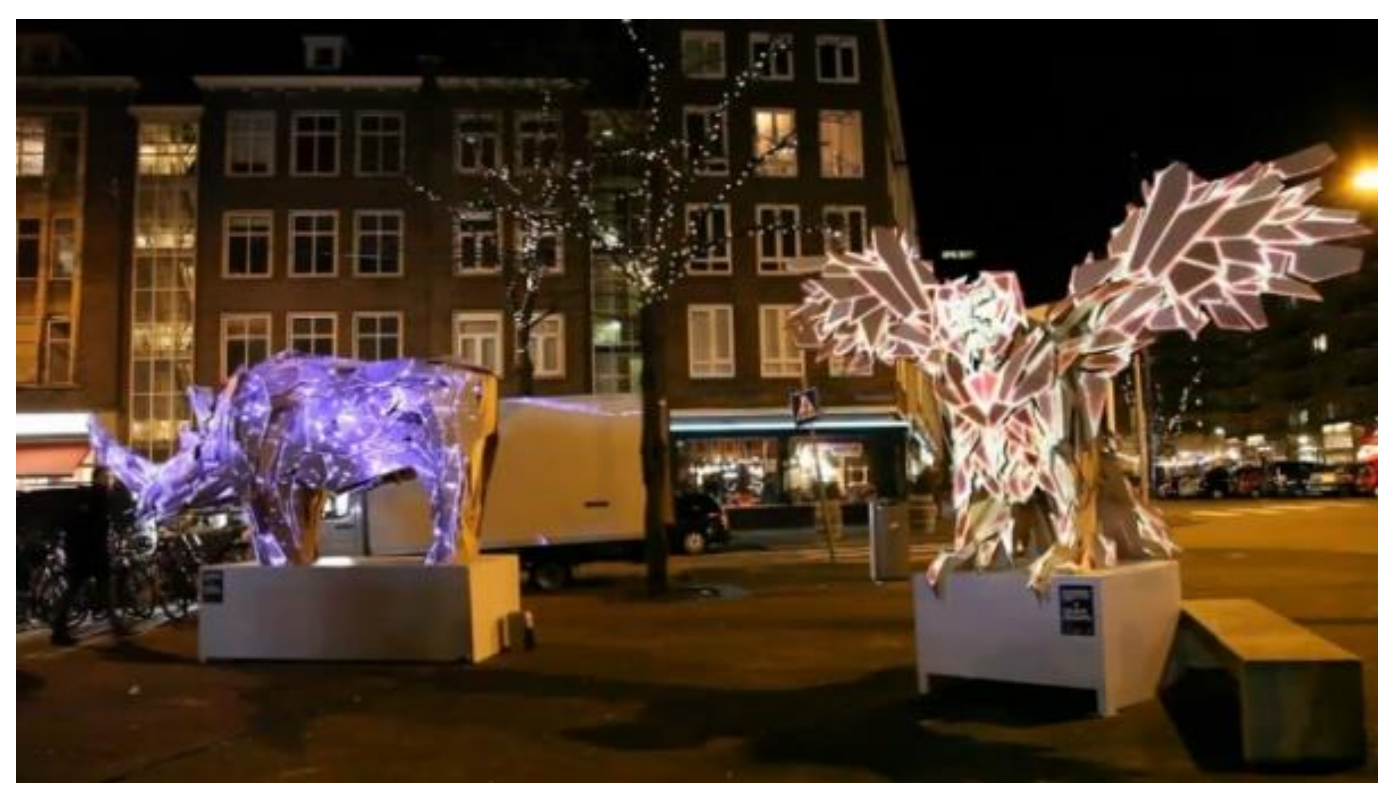

Fig. 2. Interactive Video Projection Mapping on Sculptures

The Ice Book is a miniature theatre show made of paper and light. An exquisite experience of fragile paper cutouts and video projections sweep you right into the heart of a fantasy world. It is an intimate and immersive experience of animation, book art and performance.

The Ice Book is the world's first projection mapped pop-up book. When the lights go out and a projection is beamed onto the paper stage, a dark, atmospheric story unfolds about a man on a journey through the wilderness. The piece itself features an innovative mixture of theater, video projections and paper craft and produces a truly beautiful and enchanting piece of art. 


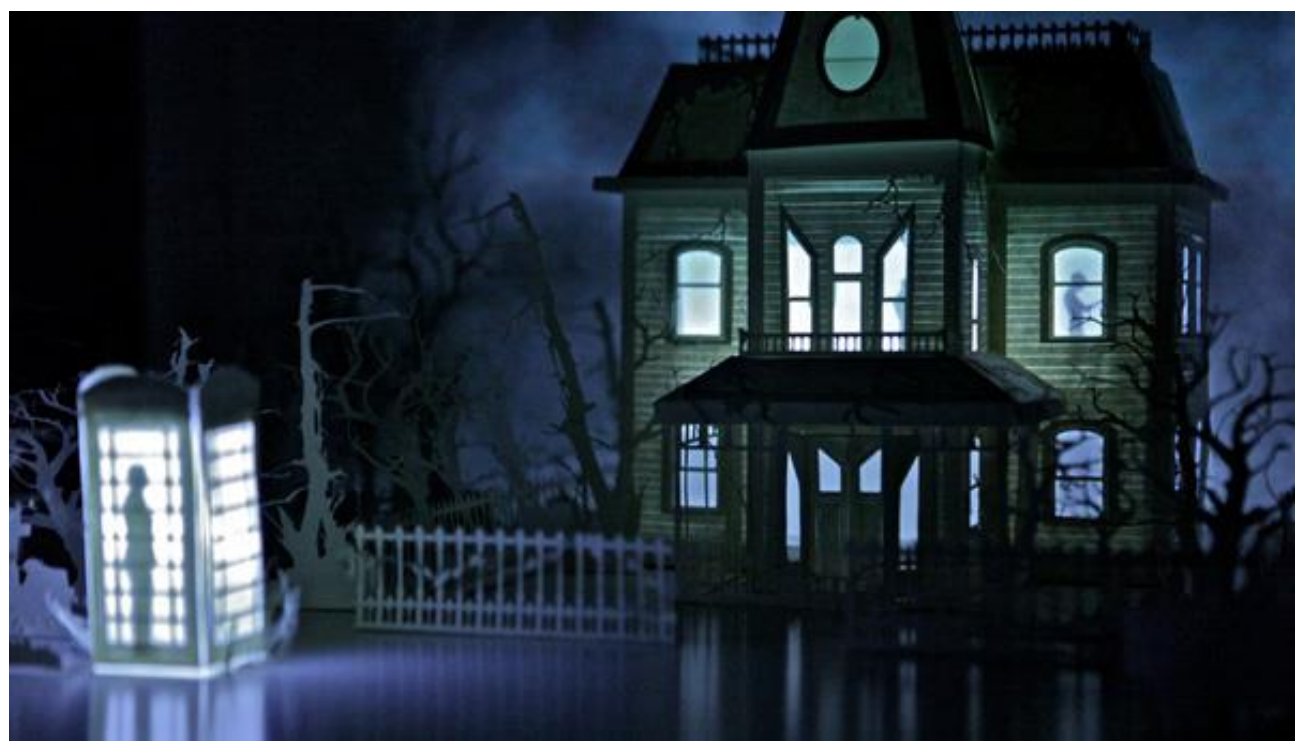

Fig. 3. Ice Book performance image

\section{Interactive Artwork}

\subsection{Background}

Although the term projection mapping is relatively new, the technique dates back to the late 1960s, where it was referred to as video mapping, spacial augmented reality, or shader lamps. By 2001, many artists began using projection mapping in artwork, and groups such as Microsoft began experimenting with it as a means of technological advancement. After the object which will be projected on is chosen or created, a virtual replica of the entire physical set up needs to be created. This project basically is inspired by projection mapping art work, Ice Book. A miniature theatre box show made of paper and entirely mini furniture is made out of wood. The whole objects in the show room are proving to be as close as the stories itself. In addition to video mapping, we implement the interactive function so that people select object and see the relative story. A joystick is an input device which is often used to control video games, and usually have one or more push-buttons whose state can also be read by the computer.

\subsection{Concept and functional}

Digital art is affected by conceptual art that is an art movement, based on the "concept" or "idea". Thus, the concept is the most important aspect for the composition of the artwork to attract viewers' attention by combining the art and 
technology. The artwork titled dynamic room is an interactive projection mapping project which people can select one object in the showroom by handling the joy stick. Each object in the space has theme: window is a rainy day, shelves are text, a wall clock is memory, a piano is sound, and a rocking chair is storytelling. As audience chooses one, the video associated with theme is playing and mapping the surface of the object.

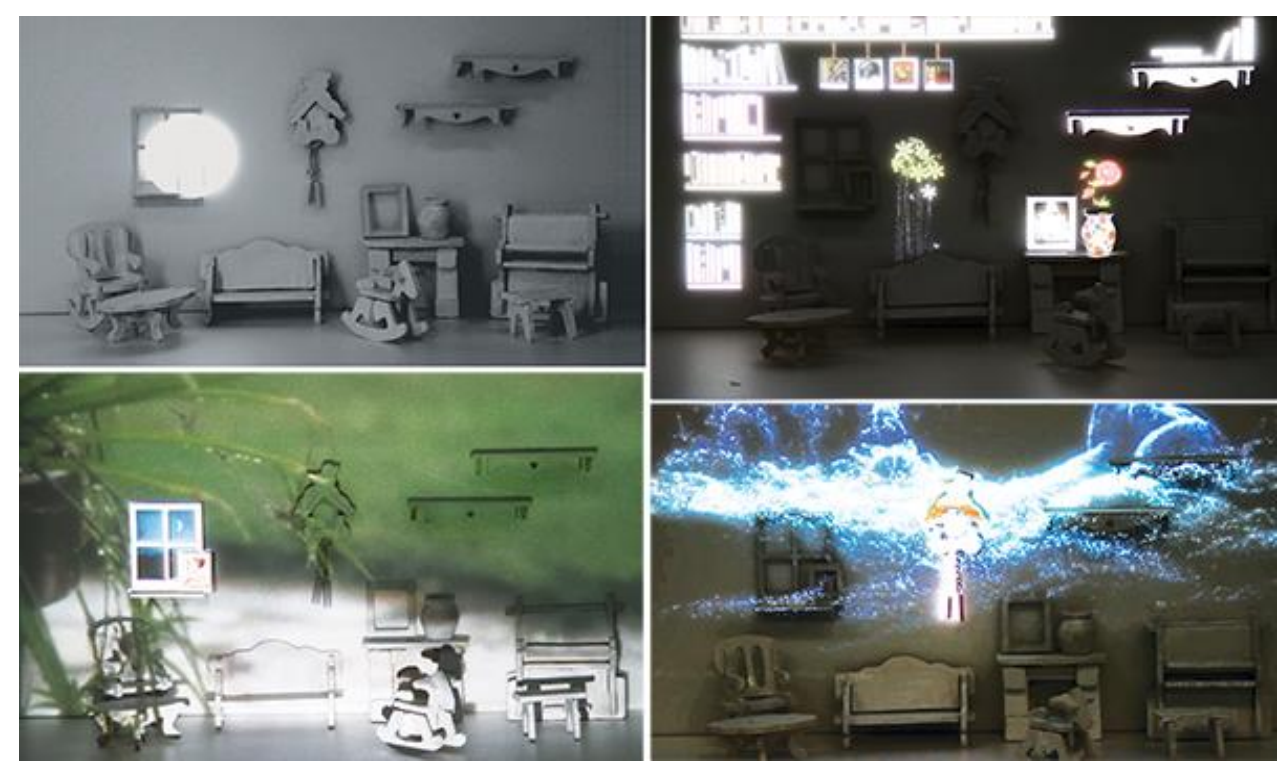

Fig. 4. Dynamic Room scene images

\subsection{Software \& Hardware}

Specialized software, MadMapper, is used to warp and mask the projected image to make it fit perfectly on irregularly shaped screens. The software can interact with a projector to fit any desired image onto the surface of that object. The important issue for an effective performance is to choose the objects to apply on artwork. In that, the artwork interacts with the audience. This interaction is provided by joy stick technique which is controlled by using VVVV program. Also, Final Cut Pro, Flash and After Effects software are used for making video related to objects. 


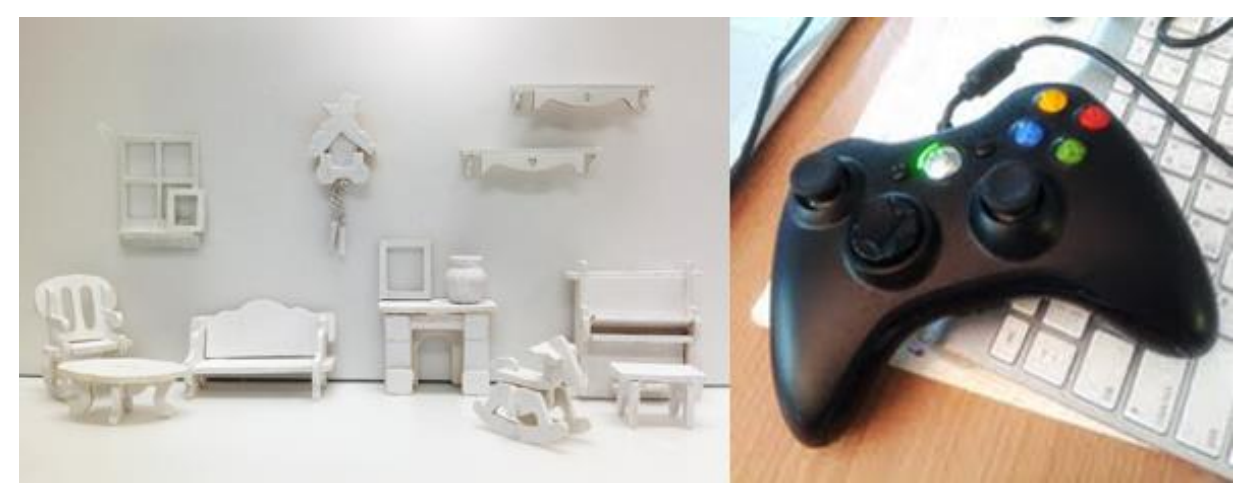

Fig. 5. Handmade showroom and Joy stick images

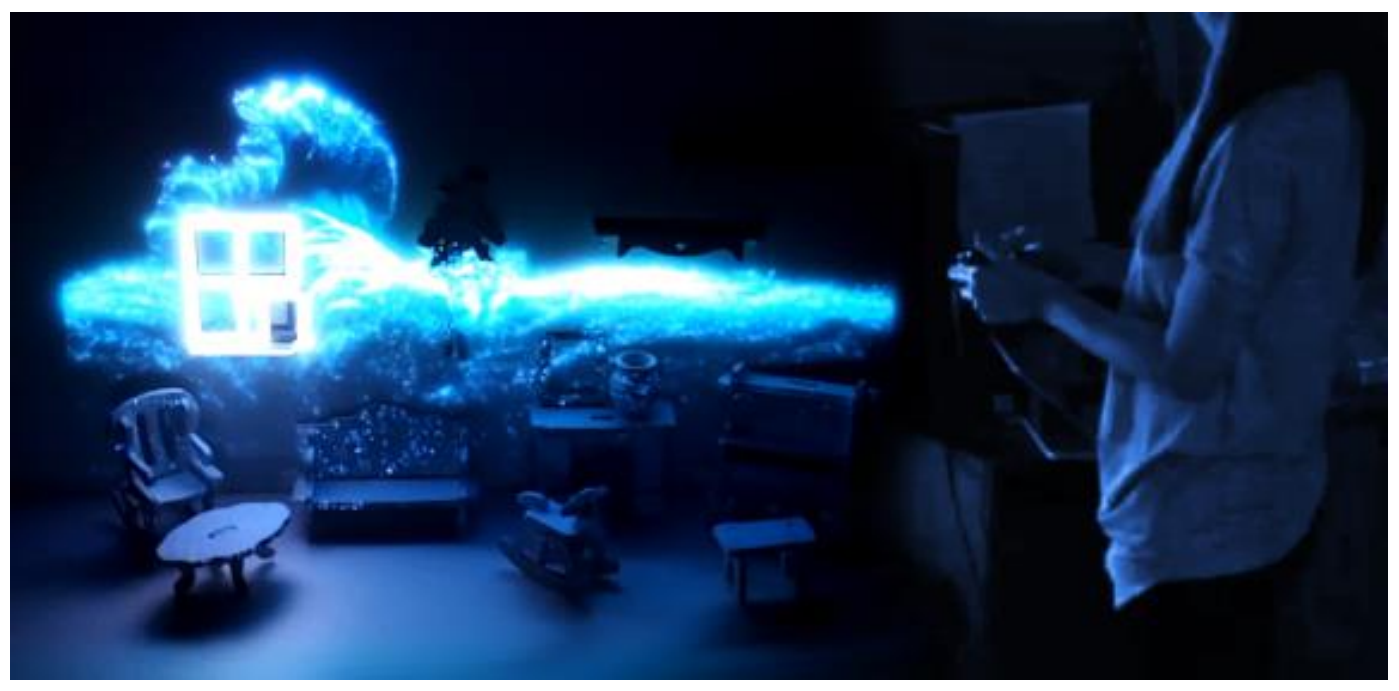

Fig. 6. Dynamic Room project working image

\section{Conclusion and future work}

A new trend of the video mapping technology help artists generates the advanced art works which are able to more directly communicate with the users. In this paper, we reviewed the media art pieces using projection mapping techniques and presented interactive video projection mapping project, "Dynamic Room". As a result, this research could suggest a new possibility and is expected to contributing the helpful study for the new media arts. In future, it will be tried to 
add various interaction ways such as networking which let user control the contents in artwork and get the feedback from the audiences who have experienced the performance.

\section{References}

[1] K. Apaza-Aguero, L. Silva, O. R. P. Bellon, Projection Mapping on Arbitrary Cubic Cell Complexes, Volume 33, number 1 (2014), 152-163.

[2] Hyeyoung Yoo and Hyunggi Kim, On Study of the Projection Mapping In Media Arts, ASTL Series International Conference Proceeding Paper (2014), Jeju National University.

[3] Navas, Suk Chon, Hohyun Lee, Joonsung Yoon, 3D ARCHITECTURAL PROJECTION, LIGHT WALL, Leonardo, Volume 44, Issue 1 (2011) $172-173$

[4] Berna Ekim, A VIDEO PROJECTION MAPPING CONCEPTUAL DESIGN AND APPLICATION: YEKPARE, Turkish Online Journal of Design, Art and Communication, Vol. 1, Issue 1(2011), 10-19

[5] http://en.wikipedia.org/wiki/Projection_mapping (2014)

[6] http://www.visualnews.com/2013/05/20/welcome-to-the-future-projection-m apped-sculptures (2013)

[7] http://www.manchesterliteraturefestival.co.uk/events/the-icebook-369 (2013)

[8] http://www.thisiscolossal.com/2011/03/interactive-video-projection-mapping -on-animal-sculptures (2011)

[9] http://www.theicebook.com (2011)

[10] http://www.ufunk.net/en/techno/urban-flipper-un-flipper-geant-et-interactif-e n-3d-projection-mapping-fete-des-lumieres-2011-a-lyon (2011)

[11] http://en.wikipedia.org/wiki/Joystick

\section{Received: August 12, 2014}

